Article

\title{
Intensification of Sulfuric Acid Leaching of Altered Ilmenite via Adding Fluoride Activator
}

\author{
Anastasiia V. Dubenko ${ }^{1}{ }^{(}$, , Mykola V. Nikolenko ${ }^{1}{ }^{\circledR}$, Oleksandr O. Pasenko ${ }^{1}$, Andrii Kostyniuk ${ }^{2, *(1)}$ \\ and Blaž Likozar 2,3 \\ 1 Faculty of Chemical Technologies and Ecology, Ukrainian State University of Chemical Technology, \\ Gagarin Avenue 8, 49005 Dnipro, Ukraine; anastasiia.dubenko@gmail.com (A.V.D.); \\ n_nikolenko@ukr.net (M.V.N.); smfs@i.ua (O.O.P.) \\ 2 Department of Catalysis and Chemical Reaction Engineering, National Institute of Chemistry, Hajdrihova 19, \\ 1001 Ljubljana, Slovenia; blaz.likozar@ki.si \\ 3 Faculty of Chemistry and Chemical Technology, University of Ljubljana, Večna pot 113, \\ 1000 Ljubljana, Slovenia \\ * Correspondence: andrii.kostyniuk@ki.si
}

check for updates

Citation: Dubenko, A.V.; Nikolenko, M.V.; Pasenko, O.O.; Kostyniuk, A.; Likozar, B. Intensification of Sulfuric Acid Leaching of Altered Ilmenite via Adding Fluoride Activator. Processes 2021, 9, 1922. https://doi.org/ $10.3390 /$ pr9111922

Academic Editor: Aneta Magdziarz

Received: 15 July 2021

Accepted: 25 October 2021

Published: 27 October 202

Publisher's Note: MDPI stays neutral with regard to jurisdictional claims in published maps and institutional affiliations.

Copyright: (c) 2021 by the authors. Licensee MDPI, Basel, Switzerland. This article is an open access article distributed under the terms and conditions of the Creative Commons Attribution (CC BY) license (https:// creativecommons.org/licenses/by/ $4.0 /)$.

\begin{abstract}
A new method of altered ilmenite processing has been studied. In this method, sulfuric acid is used as the reaction medium of the process, and fluoride ions are activators of the dissolving process of the rutile part of the ore raw material. The regression model of the sulfate-fluoride leaching process was developed and analyzed by using the response surface method of $2^{3}$ matrix. The obtained model is adequate and well describes the studied process. The influence of Ti:F molar ratio, temperature, and sulfuric acid concentration on the leaching process are investigated in this work in order to optimize the studied process. It is experimentally proved that leaching at temperatures above $100{ }^{\circ} \mathrm{C}$, at a molar ratio of Ti:F of more than $1: 2$, and the use of solutions of sulfuric acid with concentrations of more than $85 \mathrm{wt} . \%$ is not optimal because the extraction degree of titanium is reduced. The intensification of the process of sulfuric acid leaching by dividing the main stage of chemical dissolution of ilmenite into two stages was proposed. This method allows to leach up to $95.9 \%$ of titanium, which is 1.6-1.9 times higher in comparison with the classical technology of leaching altered ilmenite.
\end{abstract}

Keywords: sulfuric acid-fluoride leaching; altered ilmenite; rutile; response surface method; chemical kinetics

\section{Introduction}

Titanium is one of the most common elements in the earth's crust, in terms of content it ranks ninth among 88 other elements. Titanium metal is one of the most common structural metals (titanium metal ranks fourth after aluminum, iron, and magnesium), and titanium dioxide pigment is used in paints, cosmetics, plastics, rubber, textiles, and in the food industry [1,2]. One of the raw materials of both titanium metal and titanium dioxide is ilmenite. However, most of the ilmenite is processed to produce $\mathrm{TiO}_{2}$ pigment (about $90 \%$ of ilmenite $\left.\mathrm{FeTiO}_{3}\right)[3,4]$.

Ilmenite can undergo leukoxenization. During this process, the oxidation of ferrous iron occurs, and, as a consequence, the molar ratio in the raw material changes to $\mathrm{FeO} / \mathrm{Fe}_{2} \mathrm{O}_{3}<1$, while the "conventional ilmenite" has a molar ratio of $\mathrm{FeO} / \mathrm{Fe}_{2} \mathrm{O}_{3}>1$. This geochemical process leads to the enrichment of ore with titanium in the form of rutile. Two types of ilmenite: low-altered $\left(\mathrm{TiO}_{2}=45-53 \%\right)$ and altered $\left(\mathrm{TiO}_{2}=53-65 \%\right)$ are known [5].

The most common industrial methods of processing titanium-bearing raw materials are hydrochloric [6-11] and sulfuric acid [12-23] leaching. The hydrochloride method is limited to the use of high-quality raw materials (concentrates must have an ilmenite content of $98-99 \%$ ), because impurities can affect the stability of the process and the quality 
of the target product. The sulfuric acid method is more commonly used in industry due to the possibility of processing ore with a lower content of ilmenite. However, this method allows the process of only low-altered ilmenite, and the degree of titanium extraction does not exceed $60 \%$ [24].

The existing technology of sulfuric acid decomposition of altered ilmenite is imperfect due to the impossibility of complete leaching of the ore. Therefore, the titanium extraction degree decreases, which significantly reduces the economic feasibility and overall efficiency of the production of $\mathrm{TiO}_{2}$ pigment by the sulfuric acid method [24]. The reasons for the low titanium extraction degree using altered ilmenite can be explained by the presence of "rutile ballast", which is dissolved very slowly (practically undissolved) in $\mathrm{H}_{2} \mathrm{SO}_{4}$ under industrial conditions of leaching. This "rutile ballast" accumulates in the sludge (it is generally thought of as an industrial waste) and it leads to large losses of titanium.

Today, the fluoride processing method of ilmenite and rutile is very actively developing [23-28]. This method is very promising and has a very strong basis for the development of this technology, because it is economical, has a low amount of waste, and has the ability to recycle the main components [29-37]. For example, the authors of $[29,30,37]$ worked with titanium dioxide, which is found in industrial waste or in low-grade materials. They offered additional processing of this raw material. They also suggested using the residues of sulfate leaching into cement. Rodriguez et al. [33] show the leaching of titanium from lean ore by various leaching agents in an autoclave. The optimal process parameters were obtained to achieve $89 \%$ titanium recovery: leaching at $123{ }^{\circ} \mathrm{C}, 330 \mathrm{rpm}, 80 \mathrm{~min}$, and $1.8 \% \mathrm{w} / \mathrm{v}$ with a mixture of $15 \% \mathrm{HF}$ and $10 \% \mathrm{H}_{2} \mathrm{SO}_{4}$. The works [31,32] describe the process of titanium dioxide treatment at high temperatures: 350-600 ${ }^{\circ} \mathrm{C}$ [31] and $700{ }^{\circ} \mathrm{C}$ [32]. In the course of these processes, gaseous reaction products were formed. In our opinion, it complicates the application of this technology in practice. The studies [33-37] describe the leaching of titanium-bearing raw materials by the hydrometallurgical method using hydrofluoric acid. The optimal parameters were established, which differ due to the use of raw materials with different chemical compositions. The most common fluorinating reagents are fluorine [38], $\mathrm{HF}[39,40], \mathrm{H}_{2} \mathrm{SiF}_{6}[41,42]$, but ammonium fluoride and ammonium hydrobifluoride are now the most commonly used $[43,44]$. The use of such compounds in the ilmenite processing allows separating salts of titanium fluoride, iron fluoride, and ammonium fluoride directly during leaching. The process of initial processing of raw materials can be carried out at relatively low temperatures, which contributes to lower energy consumption $[44,45]$. However, the fluoride method also has significant disadvantages such as relatively high demand of leaching reagent and a large number of process stages. These disadvantages lead to an increase in product and technology costs compared to the method of leaching with sulfuric acid. Therefore, this method needs significant improvements.

In our opinion, the combination of the sulfuric acid method and the fluoride method will overcome the described shortcomings of both technologies. In previous works, as part of the idea of chemical activation of the process, we proved the positive effect of fluoride ions on the efficiency of altered ilmenite leaching with sulfuric acid, which was confirmed by calculations of the thermodynamic probability of reactions $[46,47]$ and kinetic studies of the process [16]. It was found that the addition of sodium fluoride to the sample of altered ilmenite, for example in a mass ratio of 1:1, increased the titanium extraction degree by almost six times in one hour of leaching.

The aim of this work is to determine the optimal process parameters of sulfate acidfluoride leaching: sulfuric acid concentration, molar ratio Ti:F, and process temperature.

\section{Materials and Methods}

\subsection{Chemical Composition of Ilmenite Concentrate}

Ilmenite concentrate from the Malyshevske deposit (Ukraine) and titanium dioxide (for optical glass melting) were utilized in the experiments. Grinding conditions and the particle size distribution of raw and ground material are described in our previous works $[15,16,47]$. 
Figures 1 and 2 show the studies of the chemical composition of ilmenite concentrate from the Malyshevske deposit $\left(48^{\circ} 29^{\prime} 21^{\prime \prime} \mathrm{N}, 34^{\circ} 5^{\prime} 27^{\prime \prime} \mathrm{E}\right.$, Ukraine) using scanning electron microscopy (SEM) with energy-dispersive X-ray spectroscopy (EDXS). Element percentages are reported with bars, which present the average value from the obtained results for the studied sample (Table 1).

Table 1. The elemental composition of ilmenite concentrate from the Malyshevske deposit.

\begin{tabular}{cccccccccccc}
\hline Element & $\mathrm{Ti}$ & $\mathrm{Fe}$ & $\mathrm{Mg}$ & $\mathrm{Mn}$ & $\mathrm{Cr}$ & $\mathrm{P}$ & $\mathrm{V}$ & $\mathrm{Al}$ & $\mathrm{Si}$ & $\mathrm{Ca}$ & $\mathrm{O}$ \\
\hline $\boldsymbol{\omega}, \boldsymbol{w t} . \%$ & 41.0 & 19.9 & 0.540 & 0.190 & 0.100 & 0.080 & 0.120 & 0.420 & 0.370 & 0.040 & 37.2 \\
\hline
\end{tabular}

It was found that the molar ratio of Ti:Fe exceeded the stoichiometric ratio by 2.4 times. This fact allows us to conclude that the ilmenite of the Malyshevske deposit is significantly altered.

The chemical composition of the ilmenite concentrate was determined at the mining and processing plant and was presented in the certificate (TУУ14-10-005-98) for the studied samples of the concentrate. Additionally, the titanium content in this concentrate was determined additionally by us with the traditional gravimetric method. The obtained data is presented in a Table $2(n=3, p=0.95)$.

Table 2. The chemical composition of ilmenite concentrate from the Malyshevske deposit.

\begin{tabular}{cccccc}
\hline Oxide & $\mathrm{TiO}_{2}$ & $\mathrm{SiO}_{2}$ & $\mathrm{Cr}_{2} \mathrm{O}_{3}$ & $\mathrm{Al}_{2} \mathrm{O}_{3}$ & Moisture \\
\hline $\boldsymbol{\omega}$, wt.\% & $68.5 \pm 1.2$ & $0.71 \pm 0.24$ & $0.14 \pm 0.07$ & $0,35 \pm 0.11$ & $0.15 \pm 0.08$ \\
\hline
\end{tabular}

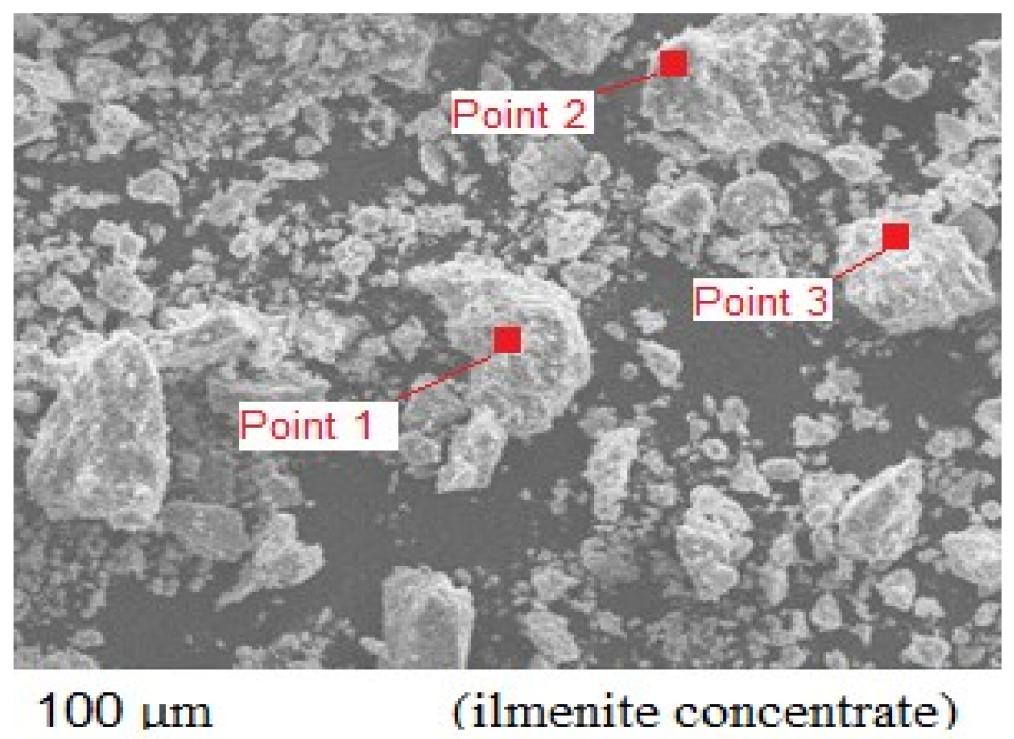

Figure 1. SEM of the ilmenite concentrate sample. 




(a)

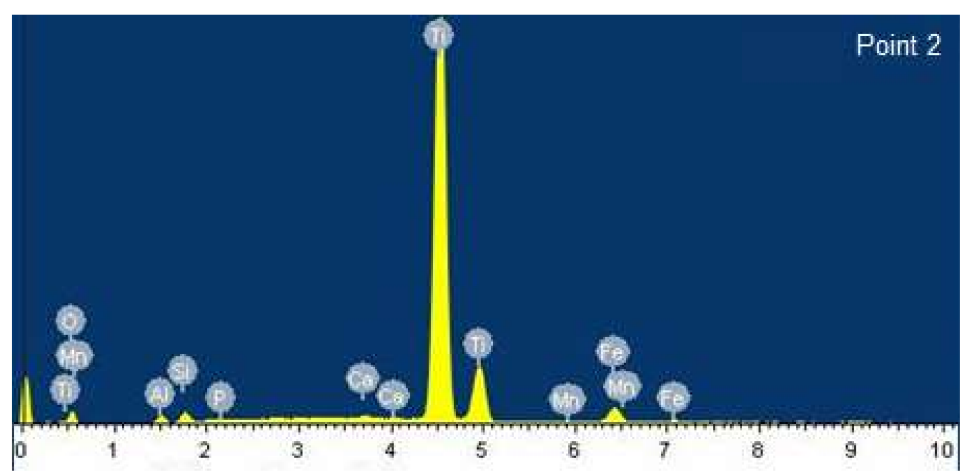

(b)



(c)

Figure 2. EDXS spectrum of the ilmenite concentrate sample with the maximum value on the scale: (a)-12389 imp; (b)-14022 imp; (c)-10965 imp.

\subsection{Experimental Methods and Procedures}

The equipment to perform the microscopy investigations and software for analyzing the diffraction patterns were described previously [13].

The titanium content in ilmenite concentrate was determined by the traditional gravimetric method with the following procedure: a weighed portion of the ilmenite concentrate was dissolved at heating in sulfuric acid with the addition of hydrofluoric acid until complete dissolution; then the reduction of $\mathrm{Fe}^{3+}$ to $\mathrm{Fe}^{2+}$ was carried out by adding metallic iron; the precipitation of metatitanic acid was carried out at $\mathrm{pH}=2-3$, which was adjusted by adding a solution of $\mathrm{NH}_{4} \mathrm{OH}$; the precipitate was filtered off and washed to remove $\mathrm{FeSO}_{4}$, excess acid, and sulfates of other metals on an ashless filter and dried; then calcined in a muffle furnace at a temperature of $900{ }^{\circ} \mathrm{C}$ in order to get rutile titanium dioxide.

Experiments on the sulfuric acid leaching with the participation of fluoride ions were carried out in the high-pressure reactor RVD-2-700 with a Teflon coating without stirring. 
The molar module of Ti:F was varied in the range of (1:1)-(1:4). The concentration of $\mathrm{H}_{2} \mathrm{SO}_{4}$ was varied from 30 to $96 \mathrm{wt} \%$, and the reaction temperature was also varied in the range of 70 to $100{ }^{\circ} \mathrm{C}$. One-factor experiments to study the effect of temperature, acid concentration, and the molar ratio of Ti:F were carried out in Teflon tubes (PTFE). The titanium content in the filtrate was also determined spectrophotometrically. The titanium content in the solution was determined photometrically in the form of a peroxide complex at a wavelength of $410 \mathrm{~nm}$ using an SF-46 spectrophotometer. The presence of iron was masked with phosphoric acid.

The extraction degree of titanium was calculated as the ratio of the amount of titanium that passed into solution after the leaching process to its content in the sample of rutile or ilmenite before the leaching process.

All the reagents used for the leaching and chemical analysis were of analytical grade ("Reachem" supplier).

The regression model of the sulfate acid-fluoride leaching process was developed and analyzed by using the response surface method of $2^{3}$ (matrix of three factors each at two levels). The molar ratio of components Ti:F, a concentration of sulfuric acid, and process temperature were chosen as independent variables. The titanium extraction degree (\%) was taken as the response of the designated experiment. The software Statgraphics Centurion XVI (Version 16.2.04) was used in this study to plot response surfaces and analyze the experimental data.

\section{Results and Discussion}

\subsection{Influence of Input Parameters of Sulfate Acid-Fluoride Leaching Process}

\subsubsection{Experimental Design}

Before using the Design of Experiments (DOE) tool, pilot experiments were performed to determine the approximate range of each independent variable. Further experiments were used for the basis of this study to find the optimal and technologically expedient parameters of the leaching process. The experimental ranges and levels of independent variables and experimental results are shown in Table 3.

Table 3. Experimental range and levels of the independent variables for Design of Experiments (DOE) matrix.

\begin{tabular}{ccccc}
\hline & Parameters & \multicolumn{3}{c}{ Coded Levels } \\
\hline Definition & Independent Variable & $\mathbf{- 1}$ & $\mathbf{0}$ & $\mathbf{+ 1}$ \\
\hline $\mathrm{x}_{1}$ & The molar ratio of components Ti:F & $(1: 1)$ & $(1: 1.5)$ & $(1: 2)$ \\
\hline $\mathrm{x}_{2}$ & The concentration of sulfuric acid, wt. $\%$ & 85 & 90 & 95 \\
\hline $\mathrm{x}_{3}$ & The process temperature, ${ }^{\circ} \mathrm{C}$ & 70 & 85 & 100 \\
\hline
\end{tabular}

As shown in Table 3, the actual levels of the process parameters are Ti:F molar ratio of components of $(1: 1)-(1: 2)$, the concentration of sulfuric acid at $85-95 \mathrm{wt} . \%$, and process temperature at $70-100{ }^{\circ} \mathrm{C}$. The actual levels and ranges of the process parameters are denoted in coded values as -1 (minimum), 0 (center), +1 (maximum). The total number of runs was eight to form a matrix design $2^{n}$, where $n=3$ ( $n$ is the number of factors). The experiments were randomly run to minimize errors between variables and eliminate biases during trials. An empirical model of the sulfate-fluoride leaching process was developed.

\subsubsection{Response Surface Methodology and Analysis}

In the present study, the relationship between response (titanium extraction degree) and three independent factors (the molar ratio of components $\mathrm{Ti}: \mathrm{F}$, the concentration of sulfuric acid, and the process temperature) was studied. Table 4 provides the performed experiments and results for each experimental run. 
Table 4. DOE matrix and experimental results for the responses.

\begin{tabular}{|c|c|c|c|c|c|c|c|}
\hline $\begin{array}{l}\text { Experimental } \\
\text { Number }\end{array}$ & $x_{1}$ & $x_{2}$ & $x_{3}$ & $x_{1} x_{2}$ & $x_{1} x_{3}$ & $x_{2} x_{3}$ & $\bar{y}, \%$ \\
\hline 1 & - & - & - & + & + & + & 7.20 \\
\hline 2 & + & - & - & - & + & - & 9.70 \\
\hline 3 & - & + & - & - & - & + & 4.10 \\
\hline 4 & + & + & - & + & - & - & 5.50 \\
\hline 5 & - & - & + & + & + & - & 17.50 \\
\hline 6 & + & - & + & - & - & + & 30.10 \\
\hline 7 & - & + & + & - & - & - & 8.50 \\
\hline 8 & + & + & + & + & + & + & 11.50 \\
\hline
\end{tabular}

A regression model of the sulfate-fluoride leaching process was developed:

$$
\begin{gathered}
y=11.7625+2.4375 \cdot x_{1}-4.3625 \cdot x_{2}+5.1375 \cdot x_{3}-1.3375 \cdot x_{1} \cdot x_{2} \\
+1.46251 .3375 \cdot x_{1} \cdot x_{3}-2.53751 .3375 \cdot x_{2} \cdot x_{3}
\end{gathered}
$$

The analysis of variance (ANOVA) for the titanium sulfate-fluoride leaching has been presented in Table 5 .

Table 5. ANOVA for the titanium sulfate-fluoride leaching process.



The correlation coefficient value $\left(\mathrm{R}^{2}\right)$ estimates the excellence of the model established by the software. As the $\mathrm{R}^{2}$ value gets closer to $100 \%$, the model is said to be better and gives predicted values closer to the actual. There was an excellent correlation between the experimental data and the predicted data as the $\mathrm{R}^{2}$ value is $98.20 \%$, which was found to be closed to $100 \%$. In addition, the closeness value of adjusted $\mathrm{R}^{2}(87.43 \%)$ is highly acceptable. Therefore, the obtained model is adequate and can be used to describe the studied process.

All variables, including the molar ratio of components Ti:F (A), concentration of sulfuric acid (B), and process temperature $(C)$, as well as interactions $A B, B C$, and $A C$, were significant based on the $p$-value less than 0.05 as is shown in Table 5 and Figure 3 (bars going beyond the vertical line of significance). 


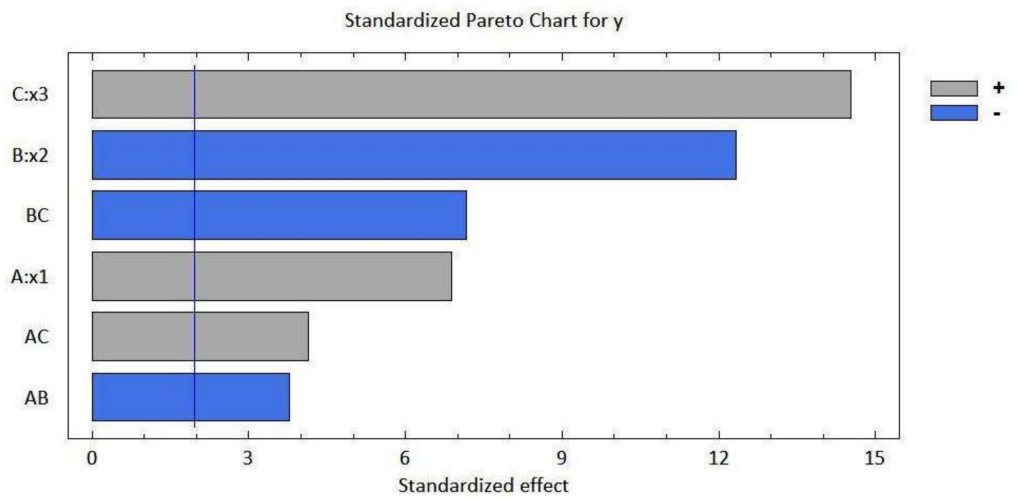

Figure 3. Analysis of the influence and significance of three independent factors and their interactions.

As shown in Figure 3, the process temperature (C) has the largest effect on the leaching process among the other parameters. The acid concentration (B) also has fairly significant effects on the studied process. Therefore, it is obvious that the synergistic interaction of the $\mathrm{BC}$ variables also has a significant effect. The molar ratio of the components (C) also has a big influence on the process.

Most of the data was found to lie along a straight line as observed in the normal probability plot of residuals shown in Figure 4a. This indicates that the selected model terms are only significant factors and the errors are normally distributed. A well-fitted regression that scattered along a straight line could be seen in the predicted (software calculated) versus observed (experimental) values plot shown in Figure $4 \mathrm{~b}$. This confirmed that the model is very well designated and adequate.

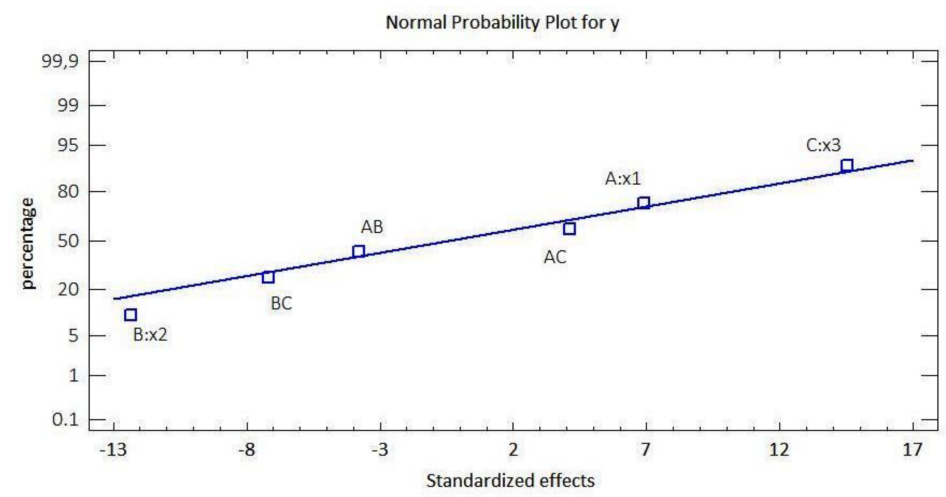

(a)

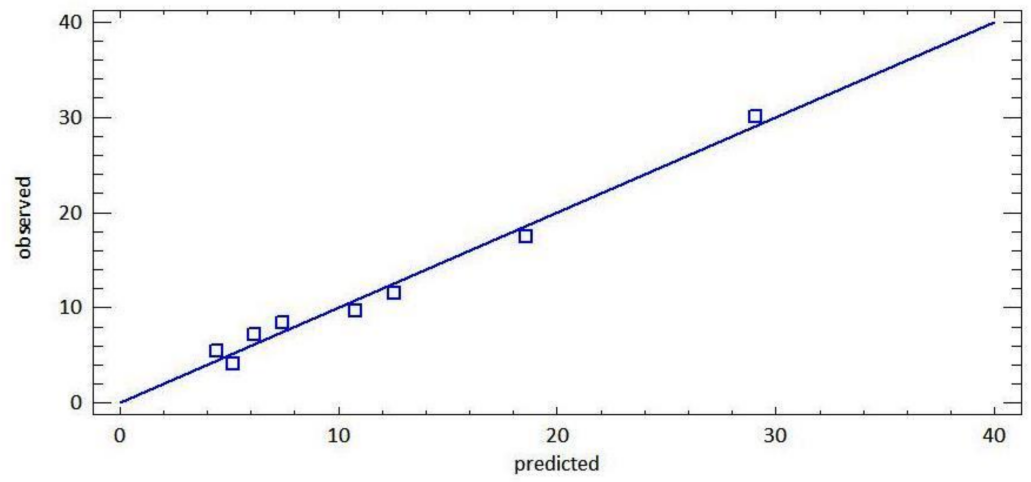

(b)

Figure 4. Normal plot of residuals (a) and predicted vs. actual plot (b). 
The two-dimensional representation of the sulfate acid-fluoride leaching process for the selected parameters is shown by the contour plot presented in Figure $5 \mathrm{a}-\mathrm{c}$. The titanium degree leaching values indicated in the plot of each contour increases $(5 b)$ or decreases (5a, 5c) almost linearly from the first to the last contour depending on chosen parameters for the data representation. The influence of chosen parameters on the studied process in the form of a 3D surface plot has been presented in Figure $5 \mathrm{~d}$. The plot shows the changes of extraction degree depend on the simultaneous influence of three factors with their various combinations.



(a)

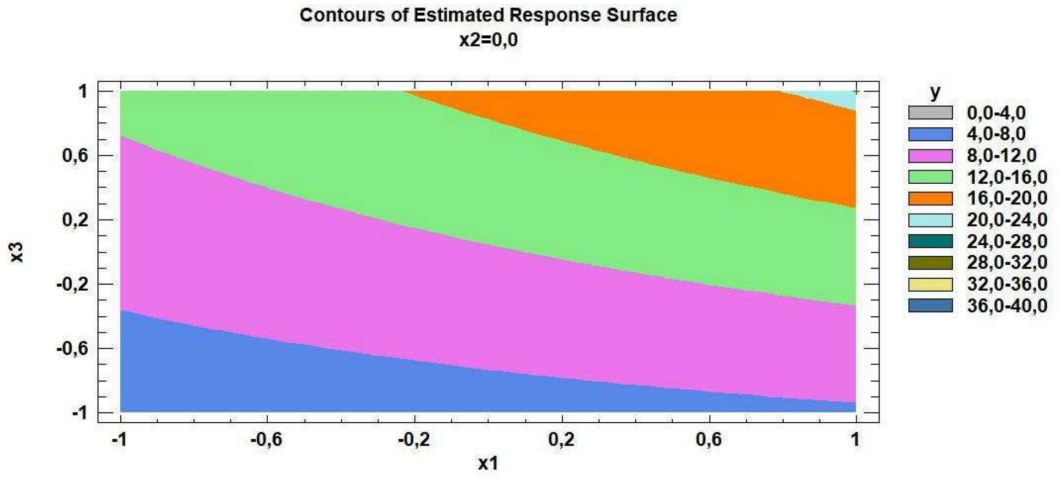

(b)

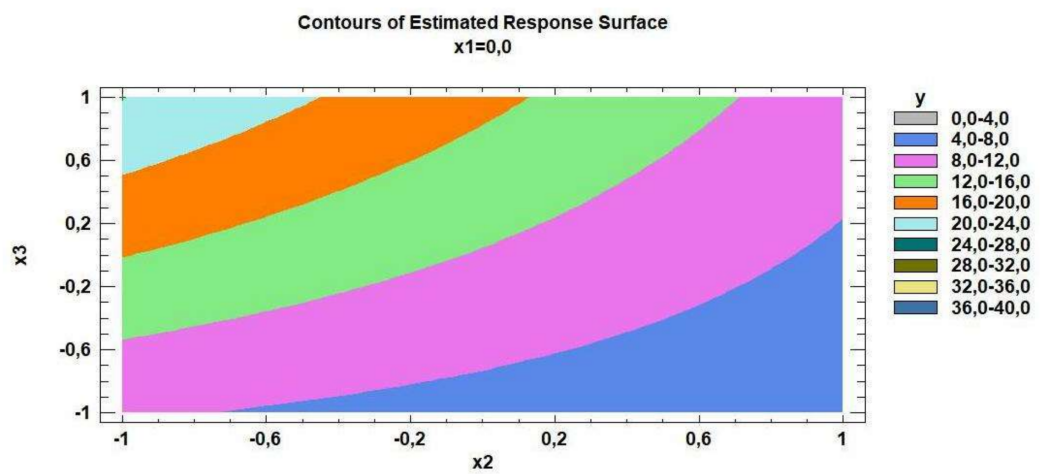

(c)

Figure 5. Cont. 


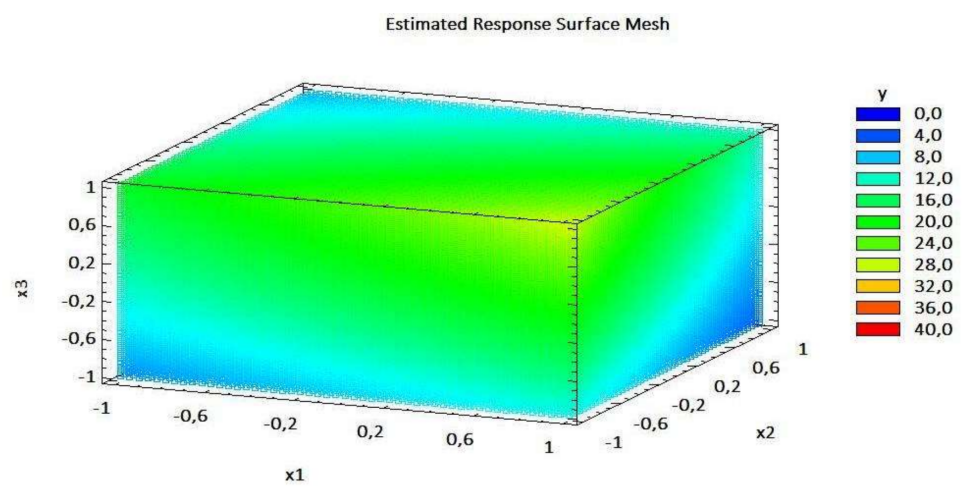

(d)

Figure 5. Contour $(\mathbf{a}-\mathbf{c})$ and $3 D(\mathbf{d})$ plots.

Thus, it can be noted that the technologically optimal parameters of the sulfate acidfluoride leaching process are the following parameters $[+1 ;-1 ;+1]$ : molar modulus of Ti: $\mathrm{F}=1: 2$, sulfate acid concentration $=85 \mathrm{wt} . \%$, and process temperature $=100^{\circ} \mathrm{C}$.

\subsection{Optimization of the Molar Ratio Value of Ti:F in the Reaction Mixture}

The dissolution of titanium dioxide in sulfuric acid with the formation of two products, $\mathrm{Ti}\left(\mathrm{SO}_{4}\right)_{2}$ and $\mathrm{TiOSO}_{4}$, was considered at the first stage of thermodynamic modeling in our previous works $[46,47]$. It is generally accepted to consider such reactions in the most simplified form, as the reactions which are accompanied by the release of water:

$$
\begin{gathered}
\mathrm{TiO}_{2}+2 \mathrm{H}_{2} \mathrm{SO}_{4}=\mathrm{Ti}\left(\mathrm{SO}_{4}\right)_{2}+2 \mathrm{H}_{2} \mathrm{O} \\
\mathrm{TiO}_{2}+\mathrm{H}_{2} \mathrm{SO}_{4}=\mathrm{TiOSO}_{4}+\mathrm{H}_{2} \mathrm{O}
\end{gathered}
$$

Obviously, water cannot be considered as a pure phase in concentrated solutions of sulfuric acid, i.e., in the standard state, due to the formation of relatively strong hydrates $\mathrm{H}_{2} \mathrm{SO}_{4} \cdot \mathrm{nH}_{2} \mathrm{O}$. Therefore, reactions (2) and (3) were rewritten taking into account the formation of sulfuric acid hydrate:

$$
\begin{gathered}
\mathrm{TiO}_{2}+4 \mathrm{H}_{2} \mathrm{SO}_{4}=\mathrm{Ti}\left(\mathrm{SO}_{4}\right)_{2}+2\left(\mathrm{H}_{2} \mathrm{SO}_{4} \cdot \mathrm{H}_{2} \mathrm{O}\right) \\
\mathrm{TiO}_{2}+2 \mathrm{H}_{2} \mathrm{SO}_{4}=\mathrm{TiOSO}_{4}+\mathrm{H}_{2} \mathrm{SO}_{4} \cdot \mathrm{H}_{2} \mathrm{O}
\end{gathered}
$$

Similarly, it is possible to write the equations for the dissolution of titanium dioxide in $85 \%$ sulfuric acid (the molar ratio of $\mathrm{H}_{2} \mathrm{SO}_{4} / \mathrm{H}_{2} \mathrm{O}=1$ ). The number of moles of sulfuric acid in such equations should generally depend on the degree of conversion of titanium dioxide and excess sulfuric acid. We considered one of the possible options which involve two acid hydrates with $n=1$ and 2:

$$
\begin{gathered}
\mathrm{TiO}_{2}+6\left(\mathrm{H}_{2} \mathrm{SO}_{4} \cdot \mathrm{H}_{2} \mathrm{O}\right)=\mathrm{Ti}\left(\mathrm{SO}_{4}\right)_{2}+4\left(\mathrm{H}_{2} \mathrm{SO}_{4} \cdot 2 \mathrm{H}_{2} \mathrm{O}\right) \\
\mathrm{TiO}_{2}+3\left(\mathrm{H}_{2} \mathrm{SO}_{4} \cdot \mathrm{H}_{2} \mathrm{O}\right)=\mathrm{TiOSO}_{4}+2\left(\mathrm{H}_{2} \mathrm{SO}_{4} \cdot 2 \mathrm{H}_{2} \mathrm{O}\right)
\end{gathered}
$$

To obtain the optimal ratio of Ti:F, experiments were performed by varying the molar ratio of Ti:F from 1:1 to 1:4 (Figure 6). The other two parameters were constant in the value determined by response surface methodology: the concentration of sulfuric acid was $85 \mathrm{wt} . \%$ and the temperature of the sulfate acid-fluoride leaching was $100{ }^{\circ} \mathrm{C}$. 


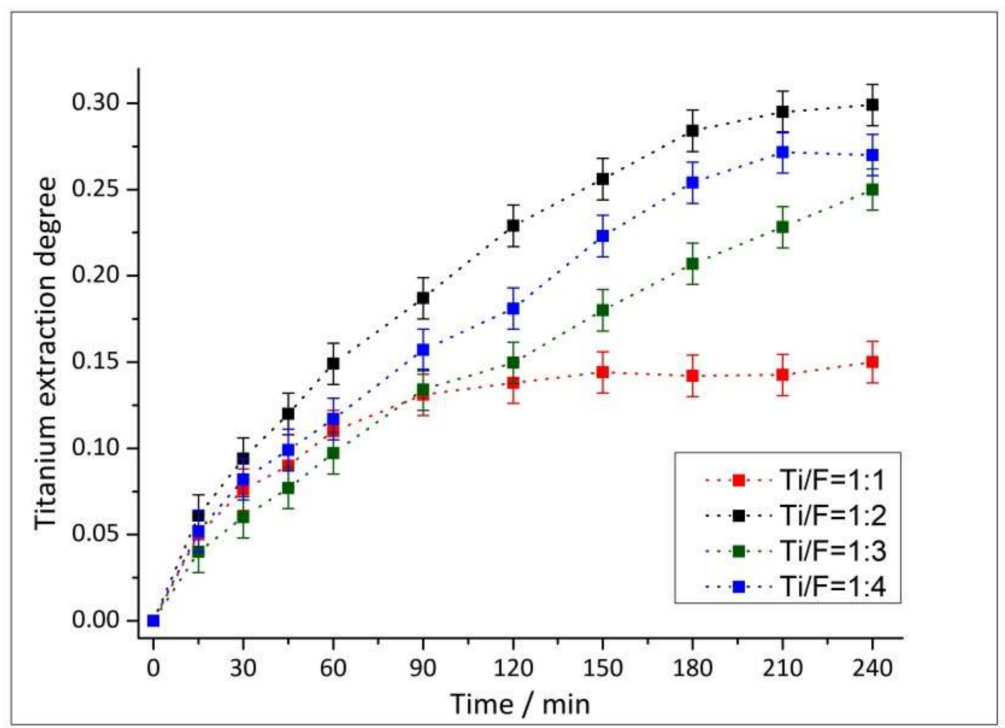

Figure 6. The dependence of the titanium extraction degree from rutile on time and the molar ratio of Ti:F, when varying the molar ratio of Ti:F from (1:1) to (1:4); the concentration of sulfuric acid was $85 \mathrm{wt} . \%$; the temperature of the sulfate acid-fluoride leaching was $100{ }^{\circ} \mathrm{C}$; the solid:liquid mass ratio was $1: 2$

It was found that the highest titanium extraction degree was observed in experiments using the molar ratio of the reaction mixture Ti: $F=1: 2$. A larger excess of sodium fluoride ( Ti:F = 1:3 and 1:4) leads to a decrease in the leaching rate. This regularity can be explained by the effect of blocking the surface of rutile with a relatively thick layer of $\mathrm{NaF}$ and $\mathrm{Na}_{2} \mathrm{SO}_{4}$ salts. This slows down the diffusion of ions and molecules involved in the chemical reaction. The low extraction degree using a molar ratio of the components of the mixture 1:1, in our opinion, is due to insufficient fluoride ions in solution to shift the equilibrium of the chemical reaction of rutile dissolution towards the formation of products. After 45 min of leaching, the kinetic curve reaches its maximum and the titanium extraction degree does not change further. In contrast to the experiment at Ti:F $=1: 1$, the kinetic curves do not reach their maximum even after $240 \mathrm{~min}$ in all other cases.

The effect of fluoride ions on the phase composition of the sludge remaining after sulfuric acid leaching of the altered ilmenite was studied by the X-ray diffraction method. A sample of sludge was obtained in the laboratory by treatment of crushed ilmenite with $85 \mathrm{wt}$ \% $\%$ solution of sulfuric acid. The process was carried out at $100{ }^{\circ} \mathrm{C}$ and a duration of one and a half hours. Then, the precipitate was separated from the solution: the first part was taken for analysis, and the second part was subjected to re-treatment with 85 wt.\% sulfuric acid with the addition of hydrofluoric acid (Ti:F = 1:2), also at a temperature of $100{ }^{\circ} \mathrm{C}$, however, with a process duration of half an hour to prevent the complete dissolution of the sample. Figure 7 shows the diffraction patterns of sludge samples before sulfuric acid-fluoride treatment and after it. 




Figure 7. Diffraction pattern of a sludge sample processed with sulfuric acid but without the addition of sodium fluoride (red curve) and with the addition of sodium fluoride (black curve).

Analysis of diffraction patterns showed that in addition to rutile and pseudorutile residues, the sludge contains an admixture of sulfuric acid-insoluble silicon oxide in the amorphous and crystalline state (PCPDFWIN № 32-0993, 82-1563). It can be seen (Figure 7) on the presented diffractograms that the reflexes of the crystalline phases of $\mathrm{SiO}_{2}$ in the range of $2 \theta=10-25^{\circ}$ disappear when adding fluoride ions to a solution of $\mathrm{H}_{2} \mathrm{SO}_{4}$. It is well explained by the solubility of $\mathrm{SiO}_{2}$ in hydrofluoric acid.

\subsection{Optimization of the Process Temperature Value}

The sulfuric acid-fluoride method was utilized for the study of the effect of temperature on the process of leaching of titanium under isothermal conditions at temperatures of $70-165^{\circ} \mathrm{C}, \mathrm{Ti}: \mathrm{F}=1: 2$ and $\mathrm{C}\left(\mathrm{H}_{2} \mathrm{SO}_{4}\right)=85 \mathrm{wt} . \%$. The results of ilmenite and rutile leaching by the sulfuric acid-fluoride method are presented in Figure 8.



(a)

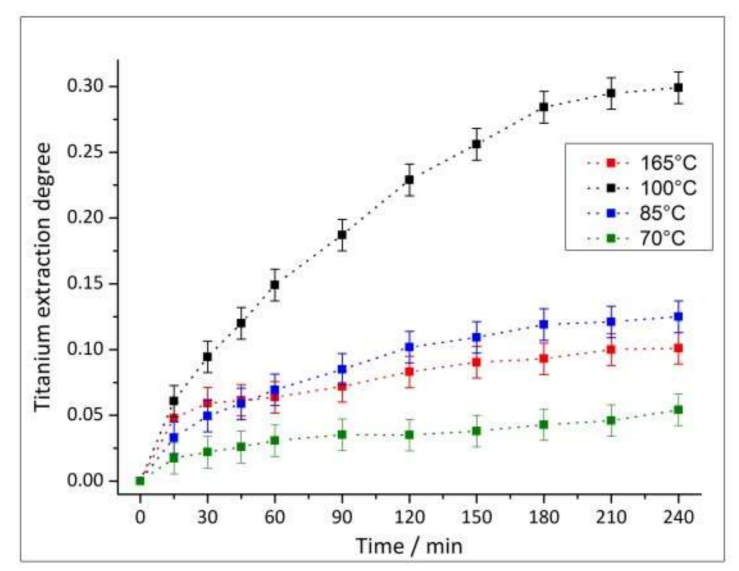

(b)

Figure 8. The dependence of the titanium extraction degree to ilmenite (a) and rutile (b) on time and temperature at $\mathrm{Ti}: \mathrm{F}=1: 2$ and $\mathrm{C}\left(\mathrm{H}_{2} \mathrm{SO}_{4}\right)=85 \mathrm{wt} . \%$; the solid:liquid mass ratio is 1:2. 
As can be seen in Figure 8, with increasing temperature, the highest titanium extraction degree into solution, both from ilmenite and rutile, is achieved during the process of sulfuric acid-fluoride leaching at $100{ }^{\circ} \mathrm{C}$.

The sharp decrease in the extraction degree at $165^{\circ} \mathrm{C}$ can be explained by the fact that in an acidic environment, fluoride ions are mainly bound to hydrogen fluoride molecules and, as a result, can evaporate rapidly from the reaction mixture. It is known that when $\mathrm{HF}$ solutions are heated, an azeotropic mixture with an $\mathrm{HF}$ concentration of $37.5 \%$ and a boiling point of $109{ }^{\circ} \mathrm{C}$ are formed. Therefore, raising the temperature above $100{ }^{\circ} \mathrm{C}$ sharply enhances the evaporation process of HF.

Additionally, it should be noted that all the curves in Figure 8 have the form of convex curves at the beginning of the leaching process, and then only the leaching curves at $165^{\circ} \mathrm{C}$ reach saturation. This can be explained by slowing down and suspending the process of rutile dissolution due to the rapid loss of fluorine ions during chemical reactions at such high temperatures.

Thus, to maximize the processing speed, it is necessary to increase the temperature of the reaction mixture to $100^{\circ} \mathrm{C}$, but further heating leads to rapid loss of $\mathrm{HF}$, which slows down and suspends the process of dissolving rutile.

\subsection{Optimization of Sulfuric Acid Concentration Value}

To determine the optimal concentration of sulfuric acid, the experiments were performed under isothermal conditions at a temperature of $100{ }^{\circ} \mathrm{C}$, molar modulus Ti:F = 1:2, and with the varying of $\mathrm{H}_{2} \mathrm{SO}_{4}$ solutions concentration from 30 to $96 \%$. The results of the kinetic studies are presented in Figure 9.



(a)

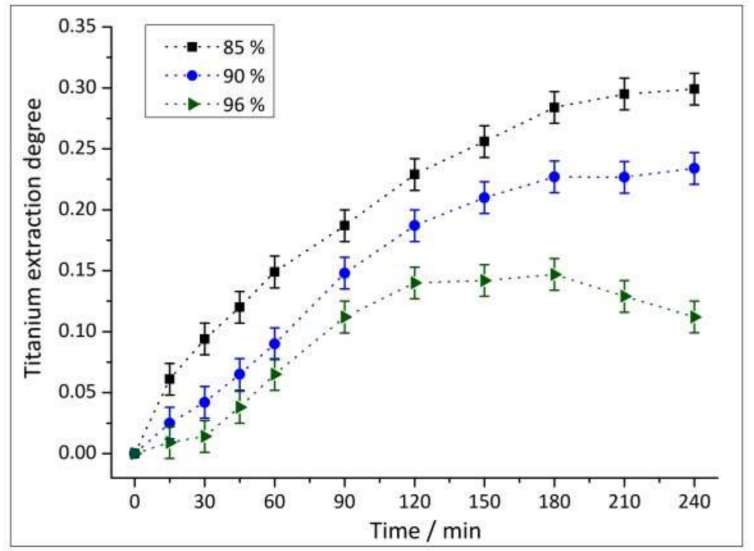

(b)

Figure 9. Dependence of the titanium extraction degree from rutile on the concentration of sulfuric acid $30-85 \mathrm{wt} \%$ (a) and 85-96 wt\% (b) at a temperature of $100{ }^{\circ} \mathrm{C}$; molar module of Ti:F = 1:2; the solid:liquid mass ratio is 1:2.

It was found that the dependences of the extraction degree on the time of rutile leaching in sulfuric acid solutions with concentrations of $30-85 \%$ have the form of convex curves (Figure 9a).

The dependences $X(t)$ are concave to the abscissa with 90 and $96 \mathrm{wt} . \%$ of acid solutions (Figure $9 \mathrm{~b}$, curves 1 and 2) compared to the data with $85 \mathrm{wt} . \%$ sulfuric acid. In this case, the rate of leaching of rutile is less.

Thus, the optimal concentration of sulfuric acid in the process of sulfuric acid-fluoride extraction is $85 \mathrm{wt} . \%$. 


\subsection{Flow Sheet of the Leaching Process of Altered Ilmenite}

Figure 10 presents a flow chart of the processing of altered ilmenite concentrate with an additional production site, for the process of the leaching sulfate-fluoride method.



Figure 10. Flow sheet of the two-stage leaching process of altered ilmenite: where: 1 -hopper for raw materials; 2 -inclined redler; 3-hopper scales for raw materials; 4-the bunker batcher for water; 5-the bunker batcher for the defoamer; 6-hopper-dispenser for sulfuric acid; 7-main reactor of leaching ilmenite concentrate; 8-reactor for Fe reduction; 9-hopper for the sludge accumulation; 10-hopper scales for sludge; 11—sludge processing reactor; 12-the bunker batcher for $\mathrm{NaF}$; 13-absorber with $\mathrm{NaOH}$; 14-hopper for the accumulation of $\mathrm{NaF}$ (for possible recirculation of the reagent activator); 15-the bunker batcher with water.

Fluoride ions will be consumed in the leaching process not only for titanium but also for iron. In order to reduce the consumption of fluorinating agent, it is advisable to divide the leaching process into two stages:

(1) sulfate acid leaching of ilmenite concentrates following the removal of iron compounds from reacting media;

(2) sulfate acid-fluoride leaching of rutile-containing sludge (not dissolved in the previous stage), in the presence of sodium fluoride.

The first stage description is as follows. The ground ilmenite concentrate from the hopper (1) goes with inclined redler (2) through hopper scales (3) to the main leaching reactor (7). Acid from the hopper (6), water from the hopper (4) and defoamer from the hopper (5) go into the reactor before the solid component. The leaching process occurs with $85 \mathrm{wt} . \% \mathrm{H}_{2} \mathrm{SO}_{4}$ at $190{ }^{\circ} \mathrm{C}$ and a mass ratio solid:liquid = 1:2. After the main reaction 
of the chemical decomposition of the ilmenite concentrate, the solution is sent for filtration, having previously reduced the iron in the reactor (8). The remains of the undissolved solid fraction (sludge) go to the hopper for sludge accumulation (9). Additional heating and maintaining the temperature in the reactor is carried out by supplying steam.

The second stage description is the next. as follows. Concentrated sulfuric acid is fed in the reactor (11) from the hopper dispenser (6). After that, the solid components are loaded into the reactor: sludge from the hopper for the sludge accumulation (9), through the dispenser (10) and sodium fluoride from the hopper dispenser (12) at a molar ratio of solid components Ti:F $=1: 2$, the mass ratio of solid:liquid $=1: 2$. This method of loading the components (liquid-solid) promotes better mixing of the reaction mixture. After that, the reactor is fed water from the hopper (15), to dilute the sulfuric acid to the needed concentration $(85 \mathrm{wt} . \%)$. This promotes the self-heating of the reaction mixture. The sulfate acid-fluoride leaching occurs at $100{ }^{\circ} \mathrm{C}$. Additional heating and maintaining the temperature in the reactor is carried out by supplying steam. After the main reaction of the chemical decomposition of the sludge, the solution is sent for filtration. Next, we propose the absorption of gaseous waste and the recycling of $\mathrm{NaF}$. The formed gaseous HF goes from the reactor (11) to the absorber (13), which contains $\mathrm{NaOH}$. The resulting sodium fluoride is fed to the storage hopper (14), where $\mathrm{NaF}$ can flow through the dosing reactor (12) into the reactor (11); thus, the fluoride reagent can be recycled.

It is found that the proposed method of processing of altered ilmenite concentrates allows us to leach up to $95.9 \%$ of titanium, which is 1.6-1.9 times higher in comparison with the classical technology of leaching of altered ilmenite.

\section{Conclusions}

The regression model of the sulfate-fluoride leaching process was developed and analyzed by using the response surface method of $2^{3}$ matrix of three factors each at two levels. The obtained model is adequate $\left(R^{2}\right.$ value is $\left.98.2042 \%\right)$ and well describes the studied process. The technologically optimal parameters of the sulfate-fluoride leaching process are the following parameters $[+1 ;-1 ;+1]$ : a molar ratio of Ti:F $=1: 2$, sulfuric acid concentration $=85 \mathrm{wt} . \%$, and the process temperature $=100{ }^{\circ} \mathrm{C}$.

We have experimentally proven that the highest titanium extraction degree was obtained at the molar ratio of the reaction mixture Ti:F $=1: 2$. A larger excess or lack of sodium fluoride leads to a decrease in the leaching rate. The highest titanium extraction degree in the solution, both from ilmenite and rutile, was achieved during the process of sulfuric acid-fluoride leaching at $100{ }^{\circ} \mathrm{C}$ and using $85 \mathrm{wt} . \%$ of sulfuric acid.

Finally, in the study of the possibility to optimize the process, it was found that increasing and/or decreasing the process temperature, acid concentration, and molar modulus of Ti: $\mathrm{F}$ is impractical because it reduces the degree of titanium extraction into solution.

The intensification of the process of sulfuric acid leaching by dividing the main stage of chemical dissolution of ilmenite into two stages is proposed:

1. Sulfuric acid leaching of the altered ilmenite concentrate is carried out under the following conditions: concentration of sulfuric acid $=85 \mathrm{wt} . \%$, process temperature $=190^{\circ} \mathrm{C}$, the mass ratio of solid:liquid $=1: 2$.

2. Sulfate-fluoride leaching of rutilized sludge (raw materials that did not dissolve in the previous stage) is carried out under the following conditions: addition of sodium fluoride to the reaction mixture in a molar ratio of Ti:F $=1: 2$ and the mass ratio of solid:liquid $=1: 2$, process temperature $=100{ }^{\circ} \mathrm{C}$, concentration of sulfuric acid $=85 \mathrm{wt} . \%$.

The proposed method of processing of altered ilmenite concentrates allows us to leach up to $95.9 \%$ of titanium, which is 1.6-1.9 times higher compared to the classical technology of leaching of altered ilmenite. 
Author Contributions: Conceptualization, A.V.D. and M.V.N.; methodology, M.V.N.; software, A.V.D.; validation, M.V.N. and O.O.P.; investigation, A.V.D. and M.V.N.; resources, O.O.P.; writingoriginal draft preparation, A.V.D. and M.V.N.; writing-review and editing, A.K.; visualization, A.V.D.; supervision, B.L.; project administration, A.K.; funding acquisition, B.L. All authors have read and agreed to the published version of the manuscript.

Funding: The work was supported by the R\&D project 24/200490 of the Ukrainian State University of Chemical Technology.

Institutional Review Board Statement: Not applicable.

Informed Consent Statement: Not applicable.

Data Availability Statement: Not applicable.

Conflicts of Interest: The authors declare no conflict of interest.

\section{References}

1. Kalashnikova, A.; Nikolenko, N.; Kalashnikov, J.; Kostynyuk, A. Rutile-anatase Composite Catalyst Formed by Coupling Anatase and Rutile Particles. Chem. Mater. Eng. 2013, 1, 88-95. [CrossRef]

2. Hasan Omidi, M.; Salmani Nuri, O.; Tavakoli, H. Optimization of Ilmenite Dissolution by Synergistic Effect of Oxalic Acid and Hydrochloric Acid for Preparing Synthetic Rutile. Int. J. Nonferrous Metall. 2018, 7, 25-38. [CrossRef]

3. Titanium Dioxide Market Size, Share \& Trends Analysis Report by Application (Paints \& Coatings, Plastics, Pulp \& Paper, Cosmetics), by Region (APAC, North America, Europe), and Segment Forecasts, 2021-2028. Available online: https://www. grandviewresearch.com/industry-analysis/titanium-dioxide-industry (accessed on 15 June 2021).

4. Belardi, G.; Piga, L.; Quaresima, S.; Shehu, N. Application of physical separation methods for the upgrading of titanium dioxide contained in a fine waste. Int. J. Miner. Process. 1998, 53, 145-156. [CrossRef]

5. Zubkov, L.B. Space Metal. All about Titanium [Kosmicheskij Metall. Vsyo o Titane]; Nauka: Moscow, Russia, 1987.

6. Liu, Y.M.; Lü, H.; Qi, T.; Zhang, Y. Extraction behaviours of titanium and other impurities in the decomposition process of ilmenite by highly concentrated KOH solution. Int. J. Miner. Metall. Mater. 2012, 19, 9-14. [CrossRef]

7. Jabłoński, M.; Przepiera, A. Kinetic model for the reaction of ilmenite with sulphuric acid. J. Therm. Anal. Calorim. 2001, 65, 583-590. [CrossRef]

8. Kostova, N.G.; Achimovičová, M.; Eliyas, A.; Velinov, N.; Blaskov, V. TiO2 obtained from mechanically activated ilmenite and its photocatalytic properties. Bulg. Chem. Commun. 2015, 47, 317-322.

9. Mehdilo, A.; Irannajad, M. Effects of mineralogical and textural characteristics of ilmenite concentrate on synthetic rutile production. Arab. J. Geosci. 2013, 6, 3865-3876. [CrossRef]

10. Wei, D.; Jun-Hui, X.; Yang, P.; Si-Yue, S.; Tao, C.; Kai, Z.; Zhen, W. Extraction of Scandium and Iron from Red Mud. Miner. Process. Extr. Metall. Rev. 2020, 1-8. [CrossRef]

11. Lavecchia, R.; Piga, L.; Pochetti, F.; Chacon, L. Production of titanium chloride by chlorination of ilmenite with carbon tetrachloride. Trans. Inst. Min. Metall. Sect. C Miner. Process. Extr. Metall. 1993, 102, 174-178.

12. Wahyuningsih, S.; Ramelan, A.H.; Munifa, R.M.I.; Saputri, L.N.M.Z.; Chasanah, U. Synthesis of TiO2 nanorods from titania and titanyl sulfate produced from ilmenite dissolution by hydrothermal method. J. Phys. Conf. Ser. 2016, 776, 1-6. [CrossRef]

13. Jabłoński, M.; Tylutka, S. The influence of initial concentration of sulfuric acid on the degree of leaching of the main elements of ilmenite raw materials. J. Therm. Anal. Calorim. 2016, 124, 355-361. [CrossRef]

14. Nie, W.; Wen, S.; Liu, D.; Zhang, Q.; Liu, J.; Feng, Q. Leaching behaviors of impurities in titanium-bearing electric furnace slag in sulfuric acid. Processes 2020, 8, 56. [CrossRef]

15. Kalashnykov, Y.V.; Nikolenko, N.V.; Kachalova, A.S.; Dubenko, A.V.; Abramova, A.M. Effect of mechanical activation of malyshevsky ilmenite on its phase composition and leaching rate. Vopr. Khimii Khimicheskoi Tekhnologii 2015, $2015,63-71$.

16. Dubenko, A.V.; Nikolenko, M.V.; Kostyniuk, A.; Likozar, B. Sulfuric acid leaching of altered ilmenite using thermal, mechanical and chemical activation. Minerals 2020, 10, 538. [CrossRef]

17. Gerasimova, L.G.; Maslova, M.V. Hydrothermal behavior of titanium(IV) sulfate solutions. Russ. J. Inorg. Chem. 2012, 57, 313-319. [CrossRef]

18. Liang, B.; Li, C.; Zhang, C.; Zhang, Y. Leaching kinetics of Panzhihua ilmenite in sulfuric acid. Hydrometallurgy 2005, 76, 173-179. [CrossRef]

19. Zhang, S.; Nicol, M.J. Kinetics of the dissolution of ilmenite in sulfuric acid solutions under reducing conditions. Hydrometallurgy 2010, 103, 196-204. [CrossRef]

20. Han, K.N.; Rubcumintara, T.; Fuerstenau, M.C. Leaching behavior of ilmenite with sulfuric acid. Metall. Trans. B 1987, 18, 325-330. [CrossRef]

21. Nikolenko, N.V.; Dubenko, A.V.; Vashkevich, E.Y.; Dmitrikova, L.V. Temperature optimum of the process of the dissolution of altered ilmenite in sulfuric acid. Vopr. Khimii Khimicheskoi Tekhnologii 2018, 3, 70-78. 
22. Liu, W.; Lü, L.; Yue, H.; Liang, B.; Li, C. Combined production of synthetic rutile in the sulfate TiO2process. J. Alloys Compd. 2017, 705, 572-580. [CrossRef]

23. Xiong, X.; Wang, Z.; Wu, F.; Li, X.; Guo, H. Preparation of TiO2 from ilmenite using sulfuric acid decomposition of the titania residue combined with separation of Fe3+ with EDTA during hydrolysis. Adv. Powder Technol. 2013, 24, 60-67. [CrossRef]

24. Goroschenko, Y.G.; Belyakova, E.P.; Kozachek, N.N.; Dvernyakova, A.A. Technical Titanium Dioxide and Its Production from Altered Ilmenite by the Sulfuric Acid Method [Tekhnicheskaya Dvuokis' Titana i eyo Poluchenie iz Izmenennogo Il'menita Sernokislotnym Metodom]; Scheka, I.A., Ed.; Naukova Dumka: Kyiv, Ukraine, 1968.

25. Gordienko, P.S.; Dostovalov, V.A.; Pashnina, E.V. Hydrofluoride method of complex processing of titanium-containing raw materials. Solid State Phenom. 2017, 265, 542-547. [CrossRef]

26. Malina, K.M. Spravochnik Sernokislotchika [Sulfur Acid Guide], 2nd ed.; Khimiya: Moscow, Russia, 1971.

27. Dorozhkin, S.V. Calcium orthophosphates in nature, biology and medicine. Materials 2009, 2, 399-498. [CrossRef]

28. Chen, B.; Bao, S.; Zhang, Y. Synergetic strengthening mechanism of ultrasound combined with calcium fluoride towards vanadium extraction from low-grade vanadium-bearing shale. Int. J. Min. Sci. Technol. 2021, in press. [CrossRef]

29. Chyliński, F.; Kuczyński, K. Ilmenite mud waste as an additive for frost resistance in sustainable concrete. Materials 2020, 13, 2904. [CrossRef]

30. Chyli 'nski, F.; Bobrowicz, J.; Łukowski, P. Undissolved ilmenite mud from $\mathrm{TiO}_{2}$ production—waste or a valuable addition to portland cement composites? Waste or a Valuable Addition to Portland Cement Composites. Materials. 2020, 13, 3555. [CrossRef]

31. Chen, D.; Jiang, Z.; Geng, J.; Zhu, J.; Yang, D. A facile method to synthesize nitrogen and fluorine co-doped TiO 2 nanoparticles by pyrolysis of (NH4)2TiF 6. J. Nanopart. Res. 2009, 11, 303-313. [CrossRef]

32. Pong, T.K.; Besida, J.; O’Donnell, T.A.; Wood, D.G. A Novel Fluoride Process for Producing $\mathrm{TiO}_{2}$ from Titaniferous Ore. Ind. Eng. Chem. Res. 1995, 34, 308-313. [CrossRef]

33. Rodriguez, M.H.; Rosales, G.D.; Pinna, E.G.; Tunez, F.M.; Toro, N. Extraction of titanium from low-grade ore with different leaching agents in autoclave. Metals 2020, 10, 497. [CrossRef]

34. Sachkov, V.I.; Nefedov, R.A.; Orlov, V.V.; Medvedev, R.O.; Sachkova, A.S. Hydrometallurgical processing technology of titanomagnetite ores. Minerals 2018, 8, 2. [CrossRef]

35. Biswas, R.K.; Habib, M.A.; Dafader, N.C. A study on the recovery of titanium from hydrofluoric acid leach solution of ilmenite sand. Hydrometallurgy 1992, 28, 119-126. [CrossRef]

36. Hansen, A.D.; Traut, E.D.; Fisher, G.T. Extraction of Titanium and Iron From Ilmenite. Tech. Rep. USA Report of Investigations No 9557 1995, 1995, 1-12.

37. Gupta, A.K.; Aula, M.; Pihlasalo, J.; Mäkelä, P.; Huttula, M.; Fabritius, T. Preparation of synthetic titania slag relevant to the industrial smelting process using an induction furnace. Appl. Sci. 2021, 11, 1153. [CrossRef]

38. Karelin, V.A.; Kameneva, O.V. Ftoridnyiy metod pererabotki rutilovogo kontsentrata [Fluoride processing method of rutile concentrate]. Bull. Tomsk Polytech. Univ. 2006, 309, 94-99. (In Russian)

39. Hansen, D.A.; Traut, D.E. The kinetics of leaching rock ilmenite with hydrofluoric acid. JOM 1989, 41, 34-36. [CrossRef]

40. Biswas, R.K.; Mondal, M.G.K. A study on the dissolution of ilmenite sand. Hydrometallurgy 1987, 17, 385-390. [CrossRef]

41. Hansen, D.A.; Traut, D.E.; Fisher, G.T. Extraction of Titanium and Iron from Ilmenite with Fluosilicic Acid. Available online: https:/ / stacks.cdc.gov/view/cdc/10135 (accessed on 22 June 2021).

42. Guo, H.; Kuang, G.; Li, H.; Pei, W.T.; Wang, H. dong Enhanced lithium leaching from lepidolite in continuous tubular reactor using H2SO4+H2SiF6 as lixiviant. Trans. Nonferrous Met. Soc. China 2021, 31, 2165-2173. [CrossRef]

43. Langley, R.H.; Schmitz, C.K.; Langley, M.B. The synthesis and characterization of some fluoride perovskites, an undergraduate experiment in solid state chemistry. J. Chem. Educ. 1984, 61, 643. [CrossRef]

44. Karelin, V.A.; Karelin, A.I. Ftoridnaya Tehnologiya Pererabotki Kontsentratov Redkih Metallov [Fluoride Concentrates], Technology for Processing Rare Metal; NTL: Tomsk, Russia, 2004; ISBN 5895031277.

45. Xiao, J.; Peng, Y.; Ding, W.; Chen, T.; Zou, K.; Wang, Z. Recovering Scandium from Scandium Rough Concentrate. Processes 2020, 8, 365. [CrossRef]

46. Dubenko, A.V.; Nikolenko, N.V.; Velichenko, A.B.; Suschinskii, A.D. Thermodynamic modeling of sulfate-acid and sulfate-fluoride leaching of titanium. Vopr. Khimii Khimicheskoi Tekhnologii 2020, 3, 69-76. [CrossRef]

47. Dubenko, A.V.; Nikolenko, M.V.; Aksenenko, E.V.; Kostyniuk, A.; Likozar, B. Mechanism, thermodynamics and kinetics of rutile leaching process by sulfuric acid reactions. Processes 2020, 8, 640. [CrossRef] 